\title{
TEORÍAS SOBRE LAS TRANSICIONES A LA DEMOCRACIA. ESTADO DE LA CUESTIÓN ${ }^{1}$
}

\author{
J. Daniel MOLINA JIMÉNEZ \\ Universidad de Salamanca
}

RESUMEN: Los procesos de transición a la democracia han sido analizados por numerosos profesionales. Este artículo pretende establecer un estado de la cuestión, a modo de inventario, de todas estas teorías para, a partir de ellas, poder establecer nuevas hipótesis en las interpretaciones históricas sobre el tema.

PALABRAS CLAVE: Transición, modernización, cambio, consolidación, democracia.

ABSTRACT: The processes of transition to democracy have been analyzed by numerous professionals. This communication aims to establish a state of the question by way of inventory, of all these theories, for, from them, to be able to establish new hypotheses in historical interpretations on the subject.

KEYWORDS: Transition, modernization, change, consolidation, democracy.

\section{INTRODUCCIÓN}

Explica Samuel Huntington en el prólogo de su obra "clásica" La Tercera ola, que "una buena teoría es precisa, austera, elegante, e ilumina las relaciones entre distintas variables conceptuales". En verdad las teorías sociológicas sobre las transiciones han servido, en numerosas ocasiones, como puntos de apoyo para los trabajos realizados por los historiadores sobre la materia. Esta comunicación pretenderá elaborar un estado de la cuestión, a modo de inventario, de las principales teorías, para a través de ellas, poder formular hipótesis nuevas y relevantes en los estudios históricos referidos a las Transiciones políticas a la democracia.

Las transiciones están delimitadas "de un lado, por el inicio del proceso de

${ }^{1}$ Recibido el 4 de julio de 2011. Aceptado en el consejo de 8 de noviembre de 2011.

${ }^{2}$ S. P. HunTINGTON (1994). La tercera ola. La democratización a finales del siglo XX. Barcelona: Paidós, p. 13. 
disolución del régimen autoritario, y del otro, por el establecimiento de alguna forma de democracia, el retorno a algún tipo de régimen autoritario o el surgimiento de una alternativa revolucionaria" "3. Morlino define transición como "un tipo de cambio más restringido y delimitado que los que hemos considerado hasta el momento, o que pertenece a un nivel de abstracción inferior. El objeto del cambio no es ya el sistema político, sino el régimen" ". Este autor entiende que para comprender el cambio se deben escrutar variables que tratan de explicar el qué, el cuánto y el cómo, es decir, habría que indicar cuáles son el objeto, el grado y las modalidades del cambio. ¿Qué cambia? Valores, normas y estructuras de autoridad. ¿Cuánto cambia? Para precisar los elementos tendríamos que tener en cuenta que un conjunto de cambios graduales puede ser tal que supere el umbral a partir del cual el cambio pasa de marginal a fundamental. En qué medida sea fundamental y en qué medida gradual, o bien qué aspectos permanecen inalterados y cuáles cambian, depende estrechamente de cómo ha tenido lugar ese cambio. ¿Cómo cambia? Haríamos referencia al modo, las dimensiones relevantes en la transición.

Por ello cuando aludamos al proceso que va desde el final de un régimen autoritario al inicio de un sistema democrático, nos referiremos a una Transición política a la democracia, para delimitar el proceso y caracterizarlo. Una Transición política a la democracia es un cambio de régimen político (en principio sólo político) que lleva a otro régimen que es democrático: ¿Qué características debemos tener en cuenta para determinar que el cambio ha sido hacia la democracia?, ¿qué factores, modelos y condiciones permiten la instauración y la pervivencia de una democracia? A todas estas preguntas trataremos de dar respuesta en los próximos apartados a partir de la compilación de las principales teorías científicas. En todo caso, como marco previo, hemos de tener en cuenta que las transiciones políticas a la democracia o las democratizaciones, transcurren necesariamente por tres etapas: a) fin de un régimen autoritario; b) establecimiento de un régimen democrático; c) consolidación de un régimen democrático.

\section{LAS CAUSAS: TESIS MODERNIZADORAS E INTERPRETACIONES POLÍTICAS}

Frecuentemente se han definido las transiciones políticas a la democracia "como

\footnotetext{
3 Ibídem, pág. 19.

${ }^{4}$ L. Morlino (1985). Cómo cambian los regímenes políticos. Madrid: Centro de Estudios Constitucionales, p. 79.
} 
el intervalo que se extiende entre un régimen político a outro",5. Esta definición es importante para precisar el término entre democratización, como proceso que lleva a la democracia, consecuencia de la anterior. En cuanto a la democracia, denominada por Robert A. Dalh ${ }^{6}$ como poliarquía, comporta una serie de instituciones y características:

1. Funcionarios electos: El control de las decisiones en materia de política pública corresponde, según lo establece la constitución del país, a funcionarios electos. 2. Elecciones libres e imparciales: Dichos funcionarios son elegidos mediante el voto en elecciones limpias que se llevan a cabo con regularidad y en las cuales rara vez se emplea la coacción. 3. Sufragio inclusivo: Prácticamente todos los adultos tienen derecho a votar en la elección de los funcionarios públicos. 4. Derecho a ocupar cargos públicos: Prácticamente todos los adultos tienen derecho a ocupar cargos públicos en el gobierno, aunque la edad mínima para ello puede ser más alta que para votar. 5. Libertad de expresión: Los ciudadanos tienen derecho a expresarse sin correr peligro de sufrir castigos severos, en cuestiones políticas definidas con amplitud, incluida la crítica a los funcionarios públicos, el gobierno, el régimen, el sistema socioeconómico y la ideología prevaleciente. 6 . Variedad de fuentes de información: Los ciudadanos tienen derecho a procurarse diversas fuentes de información, que no sólo existen sino que están protegidas por la ley. 7. Autonomía asociativa: Para propender a la obtención o defensa de sus derechos (incluidos los ya mencionados), los ciudadanos gozan también del derecho de constituir asociaciones u organizaciones relativamente independientes, entre ellas partidos políticos y grupos de intereses ${ }^{7}$.

5 G. O'Donnell; P.C. SchmitTer; L. Whitehead (comps.) (1989). Transiciones desde un gobierno autoritario: 4. Conclusiones tentativas sobre las democracias inciertas. Buenos Aires: Paidós, p. 19.

${ }^{6}$ R. DAHL (1993). La democracia y sus críticos. Barcelona: Paidós. En la página 264 el autor define las posibilidades y límites de la democracia. Distinguiendo que la misma "Puede concebirse la poliarquía de diversas maneras: como resultado histórico de los empeños por democratizar y liberalizar las instituciones políticas de los Estados nacionales; como un tipo peculiar de orden o régimen político, diferente en aspectos significativos no sólo de los sistemas no democráticos de toda laya, sino también de las anteriores democracias en pequeña escala; como un sistema de control político (a lo Schumpeter) en que los principales funcionarios del gobierno son inducidos a modificar su proceder para ganar las elecciones en competencia política con otros candidatos, partidos y grupos; como un sistema de derechos políticos (que ya hemos examinado en el capítulo 11); o como un conjunto de instituciones necesarias para el funcionamiento del proceso democrático en gran escala, necesarias para el funcionamiento del proceso democrático en gran escala".

\footnotetext{
${ }^{7}$ Ibídem, p. 267.
} 
Pérez Díaz habla de emergencia de unas tradiciones democrático-liberales en la sociedad: a) el desarrollo de un área institucional reservada o privada, libre de la intervención del gobierno; b) el desarrollo de instituciones de auto-coordinación dentro de la sociedad, tales como mercados, asociaciones voluntarias y movimientos sociales, embarcados en un complejo juego de conflictos y alianzas; y c) el desarrollo de una esfera de debate público ${ }^{8}$. Lo anterior serían instancias previas para el proceso democratizador y responderían al auge de la sociedad civil; elemento imprescindible para la instauración de un sistema democrático. Pérez Díaz distingue entre:

Sociedad civil sensu lato (sociedad civil uno) denota un entramado de instituciones sociopolíticas que incluye: un gobierno (o estado) limitado, que opera bajo el imperio de la ley, un conjunto de instituciones sociales tales como mercados (u otros órdenes espontáneos extensos) y asociaciones basadas en acuerdos voluntarios entre agentes autónomos, y una esfera pública, en la que estos agentes debaten entre sí, y con el estado, acerca de asuntos de interés público, y se comprometen en actividades públicas.

Sociedad civil dos, la cual se reduce a las instituciones sociales, tales como mercados y asociaciones, y a la esfera pública, excluyendo las instituciones estatales. En oposición a éstas últimas, aquéllas son áreas de vida social generalmente consideradas fuera del control directo por parte del Estado ${ }^{9}$.

Por ello, para este autor cabe argüir que el desarrollo, o la emergencia de una sociedad civil en sentido restringido dentro de un régimen autoritario o totalitario, prepara el camino para su transición a una democracia liberal y, en consecuencia, para el completo establecimiento de una sociedad civil en sentido amplio. Para que esto tenga lugar es preciso que se haya iniciado una transición política. La democratización está referida a aquellos procesos en que las normas y procedimientos de la ciudadanía son, o bien aplicados a instituciones políticas antes regidas por otros principios (por ejemplo el control coactivo, la tradición social, el juicio de los especialistas o las prácticas administrativas) o bien ampliadas para incluir a individuos que antes no gozaban de tales derechos y obligaciones (por ejemplo, las personas que no pagan impuestos, los analfabetos, las mujeres, los jóvenes, las minorías étnicas y los residentes extranjeros) o para abarcar problemas e instituciones que antes no participaban de la vida ciudadana (por ejemplo organismos del Estado o militares, organizaciones partidarias, asociaciones de

\footnotetext{
${ }^{8}$ V. PÉREZ DíAz (1993). La primacía de la sociedad civil. Madrid: Alianza Editorial, p. 19.

${ }^{9}$ La primacía de la sociedad civil, pp. 78-79.
} 
intereses particulares, empresas productivas, entidades educativas etc. ${ }^{10}$. Przevorski define la democracia como "un sistema donde las fuerzas políticas significativas someten sus valores e intereses a la interacción incierta de las instituciones democráticas y acaten los resultados del proceso democrático" "11. Giovanni Sartori utiliza un razonamiento comprensivo y funcionalista para explicar tres conceptos que se pueden entender por democracia: "En primer lugar, la democracia es un principio de legitimidad. En segundo lugar, la democracia es un sistema político llamado a resolver problemas de ejercicio (no únicamente de titularidad) del poder. En tercer lugar, la democracia es un ideal"12.

Pero el puro significado de las palabra - con ser útil para precisar lo que comporta un régimen de libertad - lo único que nos delimita es el significado meliorativo, no el contenido de la forma y menos la manera de alcanzarla. Es pertinente por tanto interrogarse sobre los factores que llevan a un cambio político. ¿Por qué se impulsa un proceso de democratización? ¿Qué elementos estructurales y ambientales condicionan dicho proceso? Juan Linz sintetizó ajustadamente el estado de la cuestión en torno a esta problemática de estudio: "Todo cambio de régimen político afecta a millones de vidas, removiendo un espectro de emociones, desde el miedo a la esperanza [...] Pero los hechos en sí son en realidad la culminación de un largo proceso, un cambio político que va creciendo y evolucionando a lo largo de un período de tiempo más o menos prolongado. ¿Hay una pauta común en los procesos que han llevado a un cambio de régimen, o cada uno supone una situación única?"13

En verdad las teorías que han intentado dar respuesta a las causas que llevan a la transición democrática tienen en común el que parten de una perspectiva de larga duración; si bien más o menos prolongada según los casos. Algunos autores han reflexionado sobre los procesos de cambios de una manera conjunta y global. Huntington, en su Tercera ola describe muy bien cómo estos procesos se retroalimentan y se inciden mutuamente. Este autor distingue entre causas únicas para el inicio de la transición política hacia la democracia. En este sentido, prima especialmente el contexto internacional. El caso español se encuentra inserto en un contexto favorable. De igual modo puede existir un desarrollo paralelo que pueda

${ }^{10}$ Transiciones desde un gobierno autoritario: 4. Conclusiones tentativas sobre las democracias inciertas, pág. 23.

11 A. PRZEVORSKI. Democracia y mercado. Reformas políticas y económicas en la Europa del Este y América Latina, Cambridge [etc.] Cambridge University Press, 1995, p. 86.

${ }^{12}$ G. SARTORI. Elementos de la teoría política. Madrid, Alianza Editorial, 2005, p. 29.

13 J. J. LiNZ (1987). La quiebra de las democracias. Madrid: Alianza, p. 11. 
imbuir el proceso de cambio. El autor expone lo que denomina como efecto de bola de nieve: Varias transiciones iniciadas en un corto espacio de tiempo favorecen el propio cambio político. En este sentido podemos pensar en el fin de la Dictadura de los coroneles en Grecia, la Revolución de los claveles en Portugal, y la transición vía transacción iniciada en España ${ }^{14}$.

Más allá de análisis globales que pueden propiciar un cambio político, la disyuntiva fundamental nace de la controversia entre lo concreto y lo general, lo particular y la norma... Ambos polos vienen representados por dos posturas bien definidas: las interpretaciones modernizadoras y las tesis políticas.

Los análisis de la modernización son defendidas destacadamente en la obra de Lipset $^{15}$. Pero antes de analizar las propuestas de este autor, conviene recordar una máxima que ya se ha convertido en clásica, recogida por Lipset, pero en verdad atribuible a Max Weber: "la democracia es un sistema que sólo puede existir en el

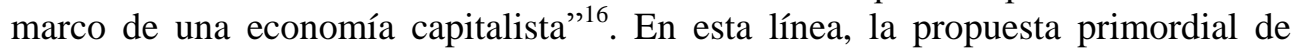
Lipset es la siguiente: "cuanto más próspera sea una nación, tanto mayores son las posibilidades de que mantendrá una democracia" ${ }^{\text {17 }}$. Para demostrar tal tesis, Lipset emplea indicadores: expresión del desarrollo económico como la riqueza, la industrialización, la urbanización y la educación. Todos estos índices demuestran cómo son más elevados en los países "más democráticos", en términos del propio Lipset, frente a los "menos democráticos". De ello se desprende que tales factores constituyen un requisito indispensable para el establecimiento de cualquier régimen democrático. Lipset emplea una serie de indicadores para medir y comparar tales factores.

Este autor enfatiza la incidencia en la educación y su relación con la democracia $\mathrm{y}$, hablando por boca de James Bryce, esta incidencia la expresa en que "la educación, si bien no hace de los hombres buenos ciudadanos, les facilita al menos que se conviertan en tales" ${ }^{\prime \prime}$. Lipset se refiere con ello a que la educación dota al individuo de mayor perspectiva de análisis, racionalidad, principios de tolerancia, y le previene de posturas extremistas. De este modo, el autor sitúa a la educación en el plano del individuo por encima de la incidencia que en él pueda tener elementos

${ }^{14}$ La tercera ola. La democratización a finales del siglo XX, pp. 42 y 43.

15 S.M. LIPSET (1977). El hombre político. Buenos Aires: Eudeba.

${ }^{16}$ Ibídem, p. 26. Cf. R. A. DAHL (1999). On Democracy. New Haven: Yale University, p. 166.

${ }^{17}$ Ibídem, p. 30.

18 Ibídem, p. 35, cita tomada por Lipset de J. BRYCE. «South America: Observations and Impressions» en Political Science Quarterly, Vol. 28, No. 3 (Sep. 1913), pp. 524-526. 
como los ingresos o el trabajo. Pero esto no quiere decir que Lipset crea en un axioma cerrado: si bien no podemos decir que un "alto" nivel de educación constituye una condición suficiente para la democracia, la evidencia de que disponemos sugiere que se halla cerca de constituir una condición "necesaria"". Con esto anticipamos las previsibles críticas de que serán objeto estas tesis de la modernización, que, de un modo no infrecuente, han sido calificadas como deterministas.

Lipset entiende estos elementos de desarrollo económico (a saber, riqueza, industrialización, urbanización y educación) como algo interrelacionado. Por ello describe este autor un proceso de evolución secular a través de tres fases, que serían, en este orden: 1) urbanización, pues las ciudades constituyen el motor de desarrollo de la economía industrial, y dentro de las ciudades se producen las otras dos fases, 2) alfabetización, 3) incremento de los medios de producción y consumo. Entre estas dos el efecto es de reciprocidad. La alfabetización es clave en este sistema porque prepara al individuo para el reto de la modernización.

Si pretendiéramos establecer una primaria valoración de la evolución de las interpretaciones sobre esta cuestión del origen de los procesos de transición, tal vez llegáramos a la conclusión según la cual, en buena medida, estos planteamientos modernizadores han sido ya superados por los enfoques que ponen el énfasis en los elementos políticos y en la incertidumbre que domina tales procesos ${ }^{20}$. Morlino ha escrito que este tipo de interpretaciones adolecen de una clara delimitación y precisión conceptual: "Existe una esfera de denotación o extensión vastísima y, paralelamente y en razón inversa, una esfera de connotación o intensión bastante restringida. Es una regla lógica elemental que a una esfera mayor de denotación le corresponde una esfera menor de connotación, es decir, un número menor de características o propiedades del concepto usado"21. De manera tangencial la crítica de Morlino alude a que las tesis de la modernización en ocasiones han caído en una semantización del léxico que ha llevado a aplicarlo de manera democrática y sobre todo generalizada al mayor número de casos posible. Morlino habla de "estirar el concepto". El resultado, inevitable para este autor, ha sido caer en imprecisiones y generalizaciones. Un segundo factor de crítica relacionado con lo anterior, aunque

${ }^{19}$ Ídem, p. 36.

${ }^{20}$ M. REDERo SAN Román (ed.). La transición a la democracia en España. Número de la revista Ayer, 15 (1994), pág. 11. Un hito clave en la superación de los planteamientos modernistas lo representó el artículo de D. A. Rustow, «Transitions to Democracy: Toward a Dynamic Model», Comparative Politics, 2 (1970), pp. 337-363.

${ }^{21}$ Cómo cambian los regímenes políticos, p. 26. 
no estrictamente consecuencia de él, es el desinterés por parte de los teóricos de la teoría del desarrollo, por la definición de términos. Para Morlino producido por tres razones: 1) El interés de estos autores ha estado totalmente absorbido por los problemas, bastante complejos, de policy-making que planteaban los numerosos países del Tercer Mundo (recordemos que las tesis genetistas son planteadas fundamentalmente por sociólogos y politólogos norteamericanos, coincidiendo con la época de la descolonización del tercer mundo iniciada tras el final de la II Guerra Mundial y que se prolonga prácticamente hasta los años 70 del siglo pasado). 2) Consecuencia de esta coyuntura histórica, muchos de los conceptos resultan préstamos de la antropología o la psicología, ya que no era posible (ni factible) centrarse en la elaboración de conceptos precisos, debido a los retos que la situación geo-política exigía. 3) Desinterés particular de la teoría por parte de muchos de los autores.

¿Pero en qué medida están superados estos enfoques de la modernización? Pues no se han dejado del todo en el olvido puesto que las nuevas interpretaciones han atacado por deterministas estos planteamientos modernizadores, apostando por la incertidumbre, por la acción individual, el papel de las élites... Pero no niegan la importancia e influencia de los factores estructurales para el advenimiento de la democracia: ya no como elementos que determinen la transición a la democracia, sí como aspectos que impulsan, favorecen o si se prefiere, simplemente inciden, en tales procesos. Pérez Díaz ha señalado el déficit de las tesis de modernización, pero también pone de manifiesto implícitamente el excesivo determinismo que supondría prestar expresa atención a las interpretaciones políticas: "El problema de las explicaciones de tipo estructural radica en la debilidad de su examen de las variables intermedias. El problema de las teorías basadas en actores es su tendencia a perder de vista los factores constrictivos, y a poner excesivo énfasis en la incertidumbre de la situación, y en la naturaleza contingente de las decisiones de los actores" $" 22$.

Dahl, por ejemplo, rechaza la relación de causalidad directa entre estos factores estructurales señalados y el proceso de transición. La relación que diseña Dahl entre ambos aspectos es menos directa: afirma que estos factores favorecen los procesos de transición y el establecimiento de una democracia. Pero Dahl es aún más preciso en sus términos, y diferencia entre los factores o condiciones que son esenciales para la democracia, y aquellas condiciones que son favorables a la misma. Los primeros serían: 1) control del ejército y la policía por cargos electos, 2) creencias democráticas y cultura política, 3) que no exista un fuerte control

${ }^{22}$ La primacía de la sociedad civil, p. 43. 
extranjero hostil a la democracia. Las condiciones favorables serían: 4) un moderno mercado económico y social, 5) un débil pluralismo sub-cultural ${ }^{23}$. Como se desprende de lo indicado, de nuevo se destaca la importancia de la educación y de la cultura política (como se veía en Lipset), también el dinamismo económico y social; la diferencia es que estas condiciones no determinan el establecimiento de una democracia. Para Dahl, tan sólo lo favorecen. Es más, la fórmula puede ver invertidos sus términos: "países con gobiernos democráticos tienden a ser más prósperos que países con gobiernos no democráticos" ${ }^{24}$. Incluso Morlino, a pesar de lo expuesto anteriormente afirma que: "Ahora está disminuyendo el interés existente hace algunos años por los países en vías de desarrollo, pero la llamada "teoría del desarrollo" está aún en condiciones de lograr algunos resultados definitivos, entre éstos, una visión clara de algunos conceptos generales, útiles para cualquier teoría del cambio político"25.

En lo que se refiere al crecimiento económico, Huntington establece varios criterios de racionalidad sobre el mismo. No todo crecimiento económico favorece la democratización: "La evidencia sugiere que la mera riqueza no puede por sí misma haber sido un factor crucial. Irán e Irak estaban en la zona de transición, pero no se democratizaron. La respuesta es que el desarrollo económico ampliamente basado en una industrialización significativa puede contribuir a la democratización, pero la riqueza derivada de la venta de petróleo (y, probablemente de recursos naturales) no lo hace. Las rentas del petróleo enriquecen al Estado: por lo tanto, aumentan el poder de su burocracia, y porque reducen o limitan la necesidad de impuestos, también reducen la necesidad del gobierno de solicitar la aprobación de sus súbditos para los impuestos. Cuanto más bajo sea el nivel de impuestos, menos razón hay para que el pueblo pida representatividad. "No a los impuestos sin representación" fue una demanda política; no a la representación sin impuestos es una realidad política. [...]

O’Donnell sin embargo afirma "que la transición desde el gobierno autoritario no constituye meramente una cuestión de desarrollo económico o complejidad sócial" ${ }^{26}$. Niega, pues, el extremo determinista, pero no desmiente la validez en cierta medida de esos factores. O'Donnell pone el acento en lo social, en la faceta de lo público, por medio del concepto que emplea de "civilidad" (que parece

23 On democracy, p. 147.

${ }^{24}$ Ibídem, p. 58.

${ }^{25}$ Cómo cambian los regímenes políticos, p. 78.

26 G. O’Donnell; P.C. SchmitTer; L. Whitehead (comps.) (1989). Transiciones desde un gobierno autoritario: 1. Europa meridional. Buenos Aires: Paidós, p. 20. 
heredado de un concepto fundamental de la sociedad romana antigua, ciuilitas). Entiende por "civilidad" una condición de estatus público que dota a una sociedad o grupo de los resortes por los cuales son capaces de liberarse de la dominación de la autoridad (o manipulación) estatal, algo que contribuye al desarrollo de la democracia ${ }^{27}$. Es importante que a la caída de un régimen autoritario se restaure la sociedad civil que, una vez consolidada de nuevo, hace improbable una vuelta atrás. ¿Por qué medios se expresa esa sociedad civil o "civilidad"? A través de la movilización y presión desde abajo, el papel de los partidos y grupos que protagonizan con el cambio la vida política...

Estos dos últimos apuntes nos ponen en la senda de otras interpretaciones que se inscriben dentro de estas nuevas propuestas. En cuanto a la presión desde abajo, destacan las interpretaciones de Tarrow. Sobre el papel de los partidos políticos, Przeworski ha formulado destacados planteamientos. En el análisis de Tarrow se parte de una premisa: "los estados fuertes con sociedades débiles producen una participación limitada [...] mientras que los estados débiles en sociedades civiles fuertes llevan a una participación aberta" ${ }^{28}$. Tarrow considera que los regímenes autoritarios desmotivan la acción política popular, si bien la represión inherente a estos regímenes puede llevar a una mayor radicalización y efectiva organización de estos movimientos. Lo fundamental en nuestro caso de las categorías presentadas por Tarrow es la que denomina acción colectiva contenciosa, que se da cuando individuos que no disponen de un acceso a las instituciones, impulsando reivindicaciones no consideradas hasta entonces, crean un movimiento que amenaza a otras fuerzas ${ }^{29}$. Y es que, como afirma Tarrow, "la acción colectiva es el principal recurso, y con frecuencia el único, del que dispone la mayoría de la gente para enfrentarse a adversarios mejor equipados" 30 .

Para Przeworski dos son los elementos fundamentales que dominan los procesos de transición que conducen al establecimiento de la democracia: 1) son procesos inseguros, marcados por la incertidumbre y lo indeterminado del resultado final, 2) son las fuerzas políticas en lucha por la defensa de sus intereses quienes dirigen tales procesos ${ }^{31}$. Przeworski recupera una frase del discurso

27 Ídem.

${ }^{28}$ S. TARROW. (1997). El poder en movimiento. Los movimientos sociales, la acción colectiva y la política. Madrid: Alianza Editorial, p. 118.

${ }^{29}$ Ibídem, p. 19.

30 Ídem.

31 A. PrZewOrSKi. (1991). Democracy and the Market: Political and Economic Reforms in Eastern Europe and Latin America. New York: Cambridge University Press, p. 10. 
inaugural pronunciado por Adolfo Suárez en las Cortes franquistas, donde se contienen ambos elementos: "el futuro no está escrito, porque sólo las personas pueden escribirlo". Este análisis de Przeworski nos sitúa ya muy próximos del proceso mismo de transición, es decir, prescindiendo de enfoques más estructurales y que se remontan a tiempos más lejanos, el estudio del papel de los protagonistas políticos nos instala ya prácticamente sobre el modo en que se desarrolla la transición. En definitiva, las causas (por qué) se relacionan estrechamente con el momento mismo y el desarrollo de la transición (cómo).

Según Przeworski, esta pugna entre intereses contrapuestos de diferentes grupos políticos que actúan movidos por ello, resulta el juego mismo de la democracia. De manera que, estas fuerzas políticas aceptarán la democracia cuando ésta, y sólo entonces, les garantice una libre competencia de oportunidades por el poder. Así, Przeworski destaca lo decisivo de la negociación (esto ya nos introduce en los modos de transición); acuña incluso el concepto de extrication para referirse a las transiciones negociadas con el régimen autoritario precedente ${ }^{32}$. Przeworski formula la clave de el surgimiento de los procesos de transición: "the strategic problem of transition is to get to democracy without being either killed by those who have arms or starved by those who control productive resources" 33 . Esta batalla se da "cuando las clases gobernantes, atrapadas en sus propias ideologías ultraconservadoras intransigentes, se vieron imposibilitadas a hacer más concessiones" ${ }^{34}$. Pérez Díaz siguiendo un modelo de sociología comprensiva establece un pequeño matiz sobre lo expresado por Przeworski, insistiendo en la idea de que la actuación de las elites responde a reacciones a circunstancias sociales: "aunque los procesos de transición política puedan ser reconstruidos ex post facto como una sucesión de decisiones críticas tomadas por las élites, sin embargo, conviene entender que aquellas decisiones son, con frecuencia, reacciones a procesos en marcha que las élites difícilmente pueden entender, y menos pueden controlar. Esto es así porque las elites suelen partir de un conocimiento limitado de sus circunstancias locales, y un entendimiento impreciso de su naturaliza ${ }^{, 35}$. De este modo entramos más en la manera en que se realiza el cambio.

32 Ibídem, p. 11.

${ }^{33}$ Ibídem, p. 51.

${ }^{34}$ Transiciones desde un gobierno autoritario: 4. Conclusiones tentativas sobre las democracias inciertas, p. 42.

${ }^{35}$ La primacía de la sociedad civil, p. 22. 


\section{MODOS DE TRANSICIÓN POLÍTICA A LA DEMOCRACIA}

Según Rustow $^{36}$, las transiciones no pueden regirse por ningún modelo como tal, predominando lo político, las estrategias de las elites y el grado de incertidumbre. Morlino de un modo genérico realiza una taxonomía general de los Estados del régimen, sea este de naturaleza democrática o no, distinguiendo 7 situaciones: 1) crisis, 2) reconsolidación, 3) hundimiento, 4) transición continua, 5) persistencia estable, 6) persistencia inestable, 7) transición discontinua ${ }^{37}$. Además, este autor, distingue una fase intermedia entre unos estados y otros: "Entre un estado y otro hay a menudo una fase de paso, en la que el régimen no ha salido aún del estado precedente y aún no ha entrado en el siguiente. Sobre todo cuando el cambio es lento, gradual y continuo. En estas fases, que pudieran constituir tantos nuevos estados intermedios como secuencias posibles existen, el régimen ya no presenta todas las características anejas al estado precedente y no posee aún las propias del estado siguiente. La duración de los estados intermedios es bastante variable. De modo que no es posible dar más indicaciones sobre este punto"38.

En todo caso, siguiendo las tesis de Rustow, la incertidumbre en una situación de cambio, es quizá lo que entra en juego en el inicio del proceso y lo que, de alguna manera, condiciona el cómo, esto es, su desarrollo. "La señal típica de que se ha iniciado una transición es que los gobernantes autoritarios, por cualquier motivo, comienzan a modificar su propias reglas con vistas a ofrecer mayores garantías para los derechos de los individuos y grupos" 39 .

Para Przevorski la liberalización "es el resultado de una interacción entre la aparición de fisuras en el régimen autoritario y la organización autónoma de la sociedad civil. Por consiguiente la movilización y las fisuras en el régimen se alimentan mutuamente" ${ }^{\prime 4}$.

${ }^{36}$ D. A. Rustow. «Transitions to Democracy: Toward a Dynamic Model». Comparative Politics, 2 (1970), pp. 337-363.

${ }^{37}$ Cómo cambias los regímenes políticos, p. 116.

38 Ibídem, p. 117.

${ }^{39}$ Transiciones desde un gobierno autoritario: 4. Conclusiones tentativas sobre las democracias inciertas, p. 20.

39. Democracia y mercado, p. 95. El autor sostiene que a causa de entender la liberalización concebida como un proceso controlado desde arriba, la aparición de movimientos autónomos constituye la prueba de que el proyecto no es, o al menos ha dejado de ser, viable. Las manifestaciones revelan un atentado contra el más sacrosanto de los valores autoritarios, el orden mismo. 
Según este autor tanto el ritmo de la liberalización como el discurso que lo sostienen son variables. En el primer caso depende de la naturaleza del poder autoritario así como de la movilización social. El discurso normalmente viene justificado por el engaño o el miedo. "En los regímenes basados en el miedo, donde las palabras están permitidas siempre que no accedan al espacio público, las causas de la disensión pueden arder sigilosamente durante largo tiempo antes de estallar en llamas" $"$.

Este autor distingue dos posibilidades en la liberalización: "integrar a los nuevos grupos en los pocos casos en que sea posible reprimir al resto, volviendo a la situación de estancamiento autoritario, o, incorporar al calendario político el problema de las instituciones, es decir, de la democracia. Las liberalizaciones o bien acaban cambiando de signo con la inauguración de sombríos periodos descritos eufemísticamente como de normalización, o dan paso a la democratización" $"$.

"¿Qué cabe esperar que suceda, entonces, bajo diferentes condiciones?" se cuestiona Przevorski. El autor trata de responder incidiendo en una variable importante para que las liberalizaciones concluyan finalmente en democratizaciones o, por el contrario, lleven a nuevos sistemas autoritarios, dicha variable es el conocimiento de las propias fuerzas y posibilidades de todos los actores en juego. "Entre éstas destacan dos: que los participantes conozcan o no la relación de fuerzas en el momento de adoptar el marco institucional y, en caso afirmativo, que esta relación sea desigual o equilibrada. Estas condiciones determinarán qué tipo de instituciones se adoptarán y la estabilidad de las mismas. De este razonamiento se desprenden tres hipótesis: si se sabe de antemano que la relación de fuerzas es desigual, las instituciones ratificarán esta relación y sólo serán estables mientras se mantengan las condiciones originarias; si se sabe de antemano que la relación de fuerzas es equilibrada, puede producirse cualquier resultado: una guerra civil prolongada, el acuerdo de establecer unas instituciones que no pueden funcionar o el acuerdo de establecer un marco constitucional que acabará imponiéndose por la fuerza de la costumbre, si la relación de fuerzas se desconoce de antemano, las instituciones incluirán amplios controles y contrapesos que mantendrán en una variedad de condiciones"43.

Para Morlino, más que de liberalización, deberíamos distinguir varias categorías del cambio:

\footnotetext{
${ }^{40}$ Ibídem, pág. 99.

${ }^{41}$ Ibídem, pág. 102.

${ }^{43}$ Democracia y mercado, p. 139.
} 
Desarrollo: Entendido como un cambio fundamental del sistema, comporta una implícita valoración positiva y se caracteriza por la diferenciación de las estructuras políticas.

$\checkmark$ La modernización es un tipo de desarrollo que ha tenido lugar en un arco histórico determinado y que se caracteriza, además de por la diferenciación, por la profunda modificación de valores, creencias e ideologías difundidas en la comunidad política, por la ampliación progresiva de distintas formas de participación, por la aparición de numerosas estructuras intermedias, por una tendencia a la centralización de las estructuras de autoridad y, en algunos casos, por la afirmación de la autonomías de ciertos subsistemas.

$\checkmark$ El crecimiento es un cambio continuo y marginal en el que la misma diferenciación no produce transformaciones profundas en el sistema.

La decadencia es un cambio marginal o fundamental del sistema, que sigue a un proceso de desestructuración o a la incapacidad para ampliar la diferenciación ${ }^{44}$.

En todo caso las liberalizaciones pueden estar protagonizadas por los duros y los blandos del régimen autoritario. Los duros "adoptan esta posición por motivos oportunistas, indiferentes a todo proyecto político de largo alcance y preocupados sólo por su propia supervivencia en los cargos y su reparto de los despojos. Si éstos fueran los únicos duros, la tarea de la transición consistiría en gran medida en determinar el costo que implica ganar su adhesión en el momento adecuado; pero hay un núcleo central de los "duros" formado por aquellos que rechazan en forma visceral al "cáncer" y los "desórdenes" de la democracia, y creen que su misión consiste en eliminar toda huella de dichas patologías en la vida política"45. Los blandos "estarán dispuestos a recurrir a la represión y tolerarán las arbitrariedades del ministerio o del organismo de seguridad correspondiente. Lo que los convierte en "blandos" es su creciente conciencia de que el régimen que contribuyeron a implantar, y en el cual por lo común ocupan cargos importantes, tendrá que recurrir en un futuro previsible a algún grado o forma de legitimación electoral. Para que su legitimación sea a la larga factible, el régimen no puede esperar demasiado sin volver a conceder ciertas libertades, por lo menos en una medida aceptable a los sectores moderados de la oposición interna y de la opinión pública internacional”46.

${ }^{44}$ Cómo cambian los regímenes políticos, p. 77.

45 Transiciones desde un modelo autoritario 4. Conclusiones tentativas sobre las democracias inciertas, p. 32.

${ }^{46}$ Ibídem, p. 33. 
Para Colomer "los partidarios o defensores de una dictadura - como los franquistas de los años sesenta y setenta - pueden protagonizar cambios de chaqueta con afluencia aceleradamente creciente cuando las probabilidades de continuidad de aquel régimen empiezan a disminuir. Ciertos factores ajenos a la firmeza de convicciones ideológicas de una gran mayoría de los autoritarios como las protestas populares, la diplomacia de otros países o la avanzada edad del dictador, pueden incitar a un sector del personal político de la dictadura a iniciar una apertura o simplemente a atenuar el control de la población y la represión de los disidentes. Esto a su vez estimula la participación popular de los actos de protesta y las presiones extranjeras" ${ }^{\prime 7}$.

Huntington no cree tan relevante la distinción entre duros y blandos del régimen. Según él, los comportamientos políticos de las elites deben delimitarse estrictamente sobre sus actitudes hacia la democratización ya que "las transiciones empiezan siendo de un tipo y acaban siendo de outro" ${ }^{, 8}$. De este modo podemos distinguir entre: ultraconservadores, reformistas liberales, reformistas democráticos y extremistas revolucionarios.

Los períodos de transición desde la dominación autoritaria están condicionados y plasmados por las circunstancias históricas que, aunque en cada país son únicas, configuran pautas predecibles y esto es así por la manera en que fue desbaratado un régimen democrático anterior; por la naturaleza y duración del período autoritario; por los medios a que apeló el régimen autoritario a fin de ganar legitimidad y maniobrar frente a las amenazas que pusieron en peligro su férreo poder; por la capacidad de iniciativa y la oportunidad con que se emprenden los movimientos tentativos hacia la apertura; por el grado de seguridad y de autoconfianza que revelan las elites del régimen, así como la confianza y aptitudes de quienes pretenden abrir el proceso político; por la inexistencia de recursos financieros; por el asesoramiento recibido de extranjeros; y finalmente por "modos" prevalecientes

47 J.M. COLOMER (1998). La transición a la democracia: el modelo español. Barcelona: Anagrama, pág. 48. Para este autor que exista o no liberalización no depende tanto de la crisis de legitimidad de la misma sino de una elección racional de las élites dirigentes. Básicamente, el compromiso de cada individuo en la acción, que es la fuente de la mayor o menor amplitud de un movimiento, depende por un lado, de sus previsiones de que la acción colectiva vaya a ser eficaz para el objetivo que se propone. Por otro lado, depende de la probabilidad de sufrir represalias o perjuicios por haber participado en la misma, en el caso de la dictadura, por ejemplo, detención policial, imposición de una multa, retirada del pasaporte, penas de prisión fusilamiento, sanción académica, despido laboral u otras. Con otras palabras más resonantes, la amplitud de la acción colectiva depende de la fe y del miedo.

${ }^{48}$ La tercera ola. La democratización a finales del siglo XX, p. 117. 
en el campo internacional, que otorgan legitimidad a ciertas formas de transición y a otras no ${ }^{49}$.

Cuando un régimen cambia, la actitud de una gran parte de la población se mantiene neutral o a la expectativa, sin identificarse con los que lo han establecido o mantenerse leal al régimen que ha caído. Esto se produce especialmente cuando el sistema de partidos del nuevo régimen no había sido capaz de cristalizar bajo su predecesor, como en el caso de un régimen autoritario que no permite a una oposición organizada participar de ninguna manera en el proceso político. En estos casos las actitudes hacia la legitimidad y eficacia del nuevo régimen con toda probabilidad se verán permanentemente conformados por estos pasos iniciales (elaboración de la constitución y su difusión). En esta etapa los nuevos gobernantes pueden iniciar políticas con un carácter socialmente constituyente, creando una sólida base de apoyo entre los que se benefician de ellos. Es también el momento en que pueden minimizar las preocupaciones de los neutrales ante el cambio de régimen.

Tres son las imbricaciones que se dan en los procesos de democratización: gobierno y oposición; reformistas y extremistas en la coalición de gobierno, y extremistas y moderados en la oposición. Sobre esta base Huntington define tres modos o modelos de transición a la democracia: Transformaciones, reemplazos y traspasos.

Para Huntington en las transformaciones, los que detentan el poder en un régimen autoritario desempeñan el papel decisivo en el fin de los mismos y su cambio por un sistema democrático. "La transformación requiere que el gobierno sea más fuerte que la oposición. Los líderes de aquellas naciones tuvieron el poder de conducir sus países hacia la democracia, si ellos lo querían. En todos los casos, la oposición era, al menos al comienzo del proceso, marcadamente más débil que el gobierno. [...]

El re-equilibrio se produce cuando el electorado está dispuesto a aprobar la transformación o el cambio de régimen, una aprobación condicionada por la confianza en la capacidad del nuevo régimen para resolver los problemas insolubles que precipitaron la crisis final. En principio, todo requiere partidos comprometidos con el orden democrático, así como aceptar límites en la interpretación más libertaria de las libertades civiles, todo para estabilizar la situación y asegurar la supervivencia del sistema". El autor sitúa el caso español dentro de este modelo.

${ }^{49}$ Transiciones desde un gobierno autoritario: 1. Europa meridional, pp. 30-60. 
"Los reemplazos -continúa Huntington- implican un proceso de transformaciones muy diferente. Los reformistas dentro del régimen son débiles, o no existen. Los elementos dominantes en el gobierno son ultraconservadores opuestos al cambio de régimen de manera acérrima. En consecuencia la democratización depende del hecho de que la oposición gane fuerza y el gobierno la pierda hasta que caiga o sea derrocado. Los grupos opositores precedentes llegan al poder, y entonces el conflicto a menudo entra en una nueva fase, cuando los grupos en el nuevo gobierno luchan sobre la naturaleza del régimen que desean establecer. En resumen, el reemplazo implica tres fases distintas: la lucha por producir la caída, la caída y la lucha después de la caída". Parece que el modelo de reemplazo no se ajusta al esquema de transición política a la democracia en España. Sin embargo, cabe cuestionarse si pudo contener algún tipo de rasgo de este procedimiento en su primera fase - no continuada después- donde la fuerza de la oposición consiguió la caída de un gobierno autoritario y claramente continuista como fue el de Carlos Arias Navarro.

Por último Huntington observa que "en los traspasos de poder, la democratización se produce por la acción combinada de gobierno y oposición. Dentro del gobierno, el equilibrio entre conservadores y reformistas es tal que el gobierno quiere negociar un cambio de régimen - a menos que la situación de predominio ultraconservador lleve al reemplazo-, pero no quiere iniciar el cambio de régimen. Tiene que ser presionando o empujando a negociaciones formales o informales con la oposición. Dentro de la oposición, los demócratas moderados son lo bastante fuertes como para prevalecer sobre los antidemocráticos radicales, pero no tanto como para derrocar al gobierno. Por eso pueden ver ventajas en la negociación". Este modelo, que Huntington no sitúa en España, contendría elementos aproximativos muy relevantes a lo sucedido con el cambio político español sobre todo a partir de las primeras elecciones de junio de 1977.

"En los traspasos que culminan con éxito, los grupos mayoritarios, tanto en el gobierno como en la oposición reconocieron que eran incapaces de determinar unilateralmente la naturaleza del futuro sistema político para su sociedad. Los líderes del gobierno y de la oposición desarrollaron a menudo estos puntos de vista, después de hacerse demostraciones de fuerza y enzarzarse en una dialéctica política. Inicialmente, la oposición solía creer que sería posible conseguir que el gobierno cayera en un momento no muy lejano. Esta creencia era en ocasiones ampliamente irreal" $" 50$.

${ }^{50}$ La tercera ola. La democratización a finales del siglo XX, pp. 120-143. 
Según Robert Dahl ${ }^{51}$ hay tres formas para hacer la transición:

1. Forma evolutiva. Basada en la apertura del sistema político, que consiste en la mayor participación ciudadana (no necesariamente son todos). Ejemplos: Reino Unido, Países Bajos y Países Escandinavos.

2. El proceso puede ser al revés: impulsar la participación ciudadana pero sin liberar el sistema. Una democracia formal, pero no práctica.

3. En otros casos la participación ciudadana y la liberalización política se dan al mismo tiempo.

En opinión de Dahl las democracias se consolidan más cuando se produce el primer proceso. Sin embargo, el más común es el segundo.

Carlos Huneeus toma de Lehmbruch, el modelo de transformación política que lleva a la democracia y que se explica mediante distintos procedimientos en orden a solucionar el conflicto político-social. Para este autor había tres estrategias de regulación del conflicto: "la jerárquico-autoritaria, que se caracteriza por una regulación desde arriba, no participativa y tiene como ejemplo los regímenes autoritarios y dictatoriales; la estrategia mayoritaria, que se caracteriza por la primera del principio de representación y la fórmula decisoria mayoritaria y tiene al parlamento británico como su mejor empleo y la estrategia proporcional o consociacional, en la cual el conflicto se regula de acuerdo al tamaño cuantitativo o cualitativo de los actores sociales y políticos y tiene a los sistemas democráticos de Holanda, Bélgica y Austria como los mejores ejemplos" ${ }^{\circledR 5}$.

En consecuencia, y siguiendo las tesis expuestas por Huneeus en su libro sobre la Transición y la Historia de la UCD, podemos plantear la democratización española en dos modelos que pueden inspirar la acción política: la mayoritaria y la proporcional. Para Huneeus "la democracia mayoritaria tenderá a crear una dinámica en dos bloques $\mathrm{y}$, por consiguiente, contiene grandes riesgos de polarización. La proporcional, por su parte, nos parece mejor orientada a la

51 On Democracy.

52 C. HuneEus (1985). La Unión de Centro Democrático y la transición a la democracia en España. Madrid, Centro de Investigaciones Sociológicas. Cita obtenida por el autor en G. Lehmbruch. Proporzdemokratie, Politisches System und politische Kultur in der Schweiz und in Österreich, Tubinga, J.C.B. MoHR (Paul Siebeck), 1967; Parteienwettbewerg im Bundestaat, STUTTGART, Verlag W. Kolhammer, 1976; «Consotiational democracy, class conflicto and the new corporatism» en P. SCHIMTTER y G. LEHMBRUCH (comps.) (1979), Trends toward corporatist intermediation, Beverly Hills, Sage Publications. 
integración en sociedades complejas o con traumas de conflictos en el pasado, pues genera una dinámica política centrípeta y no centrífuga como la mayoritaria" ${ }^{, 53}$.

Además el modelo de Lehmbruch serviría para interpretar y clasificar no sólo las estrategias de regulación del conflicto de naturaleza estrictamente política. Su interpretación es útil también para el análisis de los subsistemas. Esto permite hacer comparaciones entre subsistemas de diferentes sistemas políticos. Por ejemplo, la burocracia, independientemente del sistema político, tiende a funcionar según la estrategia jerárquico-autoritaria, lo mismo puede decirse de las Fuerzas Armadas y de las Iglesias.

Complementario a lo descrito por Huneeus, Josep María Colomer ha establecido una interpretación del modo de Transición española mediante la teoría de juegos o de otro modo, el enfoque individual de la acción colectiva que consistiría en "procesos simultáneos y complementarios de "decantamiento". Para el caso español continúa Colomer "el aumento del número de antifranquistas activos disminuyó las esperanzas de continuidad de los franquistas. Por otro lado, los cambios de chaqueta de éstos, alimentaron el anti-franquismo hasta que la creciente actividad de la oposición provocó un abandono del barco de las ratas y una celebración democrática general" ${ }^{14}$.

La creación de una nueva democracia y su consolidación después de un período relativamente corto de gobierno no democrático, con muchos líderes del régimen autoritario anterior representando importantes papeles, no es estrictamente un caso de re-equilibrio. Se distingue decisivamente de los casos en los cuales el período autocrático ha durado muchos años y la persecución de los líderes democráticos fue tal, que muy pocos retornan a la vida política. Esto nos introduce en los factores que determinan el mantenimiento y la consolidación del cambio político hacia la democracia.

\section{LA CONSOLIDACIÓN DEMOCRÁTICA: FACTORES, POLÍTICAS Y DIMENSIÓN SOCIAL DEL RECUERDO}

Muchos son los factores que pueden provocar la continuación o la interrupción de una democracia instaurada. No todas las democracias tienen los mismos problemas y cuentan con los mismos instrumentos para establecerse. Tanto Huntington como Dahl coinciden en señalar que las dos principales claves para el mantenimiento de un sistema democrático son, por un lado, cómo tratar a los

\footnotetext{
${ }^{53}$ La transición a la democracia: el modelo español, p. 11.

${ }^{54}$ La transición a la democracia: el modelo español, p. 11.
} 
funcionarios del gobierno autoritario que estuvieron abiertamente comprometidos con el régimen anterior, en ocasiones incurriendo en casos de tortura y violando sistemáticamente los derechos humanos y, en segundo lugar, cómo reducir la participación del ejército en la política y establecer un modelo profesional de relaciones cívico- militares. Dicho de otro modo, cómo lograr la imposición pacífica, contundente y duradera del poder civil sobre el estamento militar. Para Morlino, estabilidad es, como hemos ya visto anteriormente, uno de los posibles estados de un régimen político. Para este autor, estudiar la estabilidad "significa, ante todo, esforzarse por individuar las características que debe conservar un régimen para sobrevivir y las características que debe modificar para adaptarse a las nuevas condiciones ambientales. Significa analizar, a continuación, las condiciones de mantenimiento del régimen y explicar la génesis de las mismas. En otros términos, el estudio de la estabilidad se enfrenta con algunos aspectos esenciales de la dicotomía persistencia-cambio",55.

Pérez Díaz distingue "entre los procesos de transición, consolidación e institucionalización de la democracia. Estos procesos no son fases consecutivas en una secuencia, sino fases que se solapan entre sí. En el proceso de transición se establecen las reglas básicas del juego político (es decir, el régimen político) referidas tanto a las relaciones internas de la clase política, como a las relaciones entre éste y la sociedade" ${ }^{, 56}$. Para este autor "el proceso de consolidación es aquel al final del cual existe una expectativa generalizada de que aquellas reglas del juego van a ser respetadas. Esta expectativa existe en una ausencia de amenaza a la continuidad del régimen (por razón de una agresión exterior, la intervención del propio ejército, una revolución social, o actividades de partidos, o milicias, antisistema). El proceso de institucionalización del nuevo régimen es aquel a cuyo término el régimen es considerado legítimo por la mayoría de la población. En otras palabras, el nuevo régimen queda institucionalizado cuando las reglas del juego político no sólo operan de facto, sino que, además, han sido interiorizadas por los políticos y la sociedade" ${ }^{, 57}$.

Para Przevorski "la democracia está consolidada cuando la mayor parte de los conflictos se dirimen por medio de las instituciones democráticas, cuando nadie puede controlar los resultados ex post y éstos no están determinados ex ante y son relevantes dentro de ciertos límites predecibles y suscitan el acatamiento de las

${ }^{55}$ Cómo cambian los regímenes políticos, p. 130.

${ }^{56}$ La primacía de la sociedad civil, p. 17.

${ }^{57}$ Ibídem, p. 18. 
fuerzas políticas significativas ${ }^{\$ 58}$. El final del régimen autoritario según este autor no vendría tanto por su pérdida de legitimidad sino por la articulación de una verdadera alternativa.

Huntington además distingue aún otras dos categorías que pueden incidir en la consolidación. Podemos citar así problemas estructurales que prevalecieron en las democracias de la tercera ola (donde se encuentra España), incluyendo conflictos sociales, antagonismos regionales, pobreza, desigualdad socioeconómica, inflación, deuda externa, bajos niveles de crecimiento económico. A menudo, los comentaristas remarcan la importancia que estos problemas plantean a la consolidación de las nuevas democracias.

Finalmente, según Huntigton las democracias deben enfrentarse con problemas sistémicos, o de funcionamiento del sistema. Los sistemas políticos autoritarios sufren problemas derivados de su propia naturaleza, como una excesiva concentración del poder de decisión (un sistema parlamentario siempre es más apropiado - al producirse una menor concentración de poder- que un sistema presidencialista) ${ }^{59}$.

Morlino define la estabilidad como "la característica del régimen del que, en un tiempo $t$, se valora la capacidad de duración en tiempos sucesivos $t_{1}, t_{2}, t_{3}, t_{n}$. Esto es, la capacidad de duración previsible del régimen en el tiempo. Un régimen, por tanto, es estable cuando tras el examen de algunas de sus condiciones se puede predecir que persistirá" 60 . Y a fin de explicar la definición, el autor pone un ejemplo: "la estabilidad del impuesto Romano debe valorarse en relación a un momento preciso, el 8 d.C. o el 96 d.C., y su capacidad previsible de duración, a partir de aquel momento, debe juzgarse atendiendo a las condiciones presentes en ese momento" ${ }^{61}$.

La estabilidad de los regímenes democráticos depende, en primer lugar, de la posibilidad de las principales elites políticas - dirigentes políticos, militares, empresarios - de trabajar juntos para enfrentarse a los problemas de su sociedad, y abstenerse de explotar esos problemas para obtener una ventaja inmediata, material o política. Segundo, la estabilidad de la democracia depende de la capacidad del pueblo de distinguir entre el régimen, por un lado, y el gobierno o los gobernantes

\footnotetext{
${ }^{58}$ Democracia y mercado, p. 86.

${ }^{59}$ La tercera ola. La democratización a finales del siglo XX, pp. 192.

${ }^{60}$ Ibídem, p. 135.

${ }^{61}$ Ibídem, p. 136.
} 
por otro. Experiencias democráticas previas son de este modo útiles para evitar los errores pasados que llevaron a la quiebra de la democracia.

Morlino observa que "la mayoría de los autores hace referencia al apoyo, a la legitimidad, al consenso, esto es, a ese complejo proceso que concierne a las actitudes hacia el régimen de la comunidad política en general, y de la clase política en particular". Para este mismo autor, en segundo lugar, resulta un proceso fundamental que hay que considerar "es el que da pie al rendimiento, a la eficacia decisoria y a la efectividad" ${ }^{\prime 2}$.

Así una situación estable, para este autor quedaría definida del siguiente modo: "Hay una coalición dominante y de acuerdo en cuanto al régimen, entonces se creará una solución de equilibrio tal que permitiría la persistencia. Y además la persistencia será tanto más estable: a) cuando más dominante sea la coalición prorégimen, es decir, cuanto mayor sea el conjunto de recursos poseídos por los actores que participan en la coalición; y/o b) cuando en el interior de la coalición pro-régimen, exista una segunda coalición, también dominante, sobre los objetivos políticos concretos buscados por el régimen; y/o c) cuando más dominante sea esta misma coalición sobre los objetivos políticos dada la del régimen"63.

Actualmente están tomando relevancia los estudios sobre el recuerdo de unos hechos trágicos sucedidos durante un periodo de quiebra social, que sin duda marcaron la experiencia autoritaria. El paso del tiempo implica que nuevas generaciones que no tienen identificación alguna con los partidos y liderazgo anteriores a la dictadura entren en política. Nuevos líderes fundarían así un nuevo régimen que no tendrá mucho sentido que reclame ser una continuación legítima del régimen anterior y que, por tanto, representa un caso de instauración más que de restauración. La restauración plantea algunos problemas especiales creados por la necesidad de superar tensiones entre los partidos que han contribuido a la caída del régimen, de eliminar suspicacias de actos pasados cuasi leales y de evitar que se afirmen posturas ideológicas que contribuyeron a la crisis. En todo esto, se notarán las influencias de lo que los líderes del régimen restablecido hayan aprendido de la experiencia pasada. A este respecto, la instauración de un nuevo régimen por nuevos hombres puede tener algunas ventajas para la consolidación de la democracia. Por otra parte, los que vivieron crisis fatales es más probable que comprendan mejor el tipo de conductas que llevaron a la caída de la democracia, tienen más experiencia en los procedimientos políticos democráticos y son mejores

${ }^{62}$ Cómo cambian los regímenes políticos, pp. 171-173.

${ }^{63}$ Ibídem, pag. 278. 
parlamentarios. Pueden aportar conocimiento y mayor pragmatismo a la consolidación del régimen, evitando de esta manera algunas de las dificultades que pueden surgir en el período de consolidación de regímenes democráticos nuevos y que contribuyeron a la crisis anterior.

Es evidente que para cualquier sociedad no es ejercicio de rutina administrar el miedo por cuanto todo aquello que no sucede y pueda pasar, lo que nunca pasa, lo que siempre termina viniendo. La memoria de lo amargo está siempre abocada a la incertidumbre del asalto de los sentimientos del áspero dolor de las percepciones de un hecho traumático.

Barahona de Brito $^{64}$ ha teorizado sobre las políticas hacia el pasado en sociedades en procesos de transición hacia la democracia. Es frecuente que los hechos punitivos del pretérito autoritario, sangriento o dictatorial, sean tratados a través de juicios, purgas, comisiones de verdad, compensaciones financieras a las víctimas, lugares del recuerdo... Estas políticas pueden ser realizadas de manera individual, ante la negativa pública para cubrir una demanda social más o menos visible, o bien por parte del Estado, en orden a legitimar el régimen democrático, o bien por razones de convivencia social (se han venido realizando de manera diversa atendiendo a las distintas coyunturas históricas y la preponderancia de los distintos actores sociales). De manera que, encontramos una serie de límites y posibilidades según sean los procesos de transición. En este sentido, cuanto más debilitada o deslegitimada llega la vieja elite dictatorial, mayor y más amplio será el campo de maniobra para las políticas de verdad. Otros factores que de manera decisiva pueden influir tanto en transiciones pactadas como las producidas por ruptura, son el grado de creencia real en el nuevo sistema democrático por parte de las nuevas elites, las leyes generales (constituciones), y otros marcos legales que durante el proceso se puedan establecer, la tradición democrática de esa sociedad (existencia o no de experiencias democráticas previas), así como el tipo de régimen saliente, (dictadura militar, corporativismo autoritario, sultanismo, régimen de socialismo real...), en este sentido, si hablamos de sistemas muy restrictivos donde hay una ausencia en el cumplimiento de los derechos humanos, es posible que las demandas y las reivindicaciones de justicia, verdad y memoria histórica sean elevadas.

Por el contrario, en regímenes de tinte autoritario, la actitud de apatía social suele ser frecuente y las políticas de la memoria, escasas. De igual modo, puede jugar un papel destacado los condicionamientos inmediatos, esto es, tanto el grado

64 A. BARAHONA DE BRITo y Otros (2002). Las políticas hacia el pasado. Madrid: Destino, pp. 29-70. 
de implicación de diversas instituciones en el régimen anterior (ejército, Iglesia, medios de comunicación...), a mayor implicación, mayor resistencia a la revisión del pasado, así como las prioridades de las elites de una democratización para la convivencia como factor primordial, se desprenderán escasas demandas sobre el pasado. Sin embargo, puede de igual modo darse una democratización profunda donde el factor motor del proceso pasa a ser la política de la memoria. 